\title{
Large enteroviral vaccination studies to prevent type 1 diabetes should be well founded and rely on scientific evidence
}

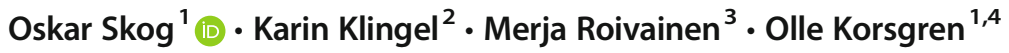 \\ Received: 6 February 2019 / Accepted: 8 February 2019 / Published online: 27 February 2019 \\ (C) Springer-Verlag GmbH Germany, part of Springer Nature 2019
}

Keywords Autoimmunity $\cdot$ Beta cells $\cdot$ DiViD study $\cdot$ Enterovirus $\cdot$ Pancreas $\cdot$ Prevention $\cdot$ Type 1 diabetes $\cdot$ Virus $\cdot$ VP1

\author{
Abbreviations \\ IHC Immunohistochemistry \\ PKR Protein kinase $\mathrm{R}$ \\ VP1 Viral protein 1
}

To the Editor: We read with great interest the For Debate article by Dunne et al [1] and fully agree with the conclusion that intervention studies using a vaccine or antiviral drugs represent the way forward to finally establish whether enterovirus plays a role in type 1 diabetes. While we welcome and support such initiatives, we consider it crucial that funders investing in the huge vaccination trials required to prove or disprove the link are provided with solid scientific evidence. Also, in the risk-benefit analysis and ethical considerations, it is essential that the available evidence is viewed critically. Therefore, we feel compelled to point out some issues regarding the evidence cited in the article by Dunne et al.

First, the sequence data of the enterovirus isolated by Dotta et al from an individual with recent-onset type 1 diabetes [2] shared $99 \%$ identity with the coxsackievirus B4 prototype strain JVB Benschoten, originally isolated in 1951, clearly

Oskar Skog

oskar.skog@igp.uu.se

1 Department of Immunology, Genetics and Pathology, The Rudbeck Laboratory C11, Clinical Immunology, Uppsala University, Dag Hammarskjölds väg 20, 75185 Uppsala, Sweden

2 Institute for Pathology and Neuropathology, University Hospital Tuebingen, Tuebingen, Germany

3 National Institute for Health and Welfare, Helsinki, Finland

4 Department of Clinical Chemistry and Transfusion Medicine, Institute of Biomedicine, University of Gothenburg, Gothenburg, Sweden indicating that it was in fact a laboratory contaminant. This is well known and non-controversial among virologists and others within the field [3-5] and we find it problematic that this paper is uncritically cited as supporting evidence for the presence of pancreatic enterovirus in type 1 diabetes.

Second, in the Diabetes Virus Detection (DiViD) study, we detected enterovirus RNA with RT-PCR in pancreatic tissue samples from only one of the six patients with recent-onset type 1 diabetes [6]. This patient was also RT-PCR-positive for enterovirus RNA in peripheral blood mononuclear cells, suggesting that the positive signal could have come from infected circulating blood cells present in the pancreas, particularly given that this biopsy was collected as a surgical specimen and not perfused with preservation solution to remove blood, as is usually done during organ procurement for transplantation. The reported, and frequently cited, enterovirus RNA-positive samples from four out of six DiViD patients were from the culture medium of isolated islets. These islets were isolated from the tip of the pancreatic tail under non-sterile conditions in a research laboratory for the purpose of functional islet studies [7]. The enterovirus-negative islets from six non-diabetic organ donors [6], referred to by Dunne et al, were isolated in our Good Manufacturing Process (GMP) facility for the purpose of clinical islet transplantation and, therefore, these results cannot be used to rule out the possibility of viral contamination in the culture medium of islets isolated from the type 1 diabetic individuals. Also, the discrepancy in PCR positivity between tissue samples and the culture medium of isolated islets is difficult to explain by a difference in sensitivity [8], and the possibility that the positive signal was derived from contaminating viral sequences introduced during islet isolation or culture cannot be excluded. Other studies (not cited in the article by Dunne et al) have failed to find evidence of enterovirus RNA in pancreatic tissue from individuals with type 1 diabetes [8-11] or reported no difference between type 1 diabetes and non-diabetic control individuals [12]. 
Third, the combined virus culture-PCR approach, stated in the article by Dunne et al as detecting enterovirus sequences in samples from all six type 1 diabetes pancreases included in the DiViD study, has only been published as an abstract [13], and so the validity of the results cannot be evaluated. It will be essential to compare the nucleotide sequences of the amplified enterovirus with the amplicons (located in the $5^{\prime}$ non-coding region of the enterovirus genome) previously reported in the DiViD islet supernatants [6]. In addition, sequencing of coding regions of the detected viruses would allow genotyping and comparison with previous isolates and laboratory strains. It is likely that enough viral genome would be obtained for amplification and sequencing if, as according to the article by Dunne et al, the virus could be isolated and propagated between cell cultures. While this approach sounds promising, it is of low value as evidence for enterovirus infection of islets at type 1 diabetes onset until these data are published and available for review by the scientific community.

Fourth, we have previously questioned the validity of immunohistochemistry (IHC) staining for the enterovirus viral protein 1 (VP1) in the human pancreas and have shown that the antibody used (clone 5D8/1, Dako) can cross-react with mitochondrial antigens [14]. In addition, this antibody was found to have strong cross-reactivity with cellular proteins in the heart of humans and mice [15]. It has been argued that, under specific conditions, this antibody can still be used to detect enteroviruses in the pancreas [16]. However, the presence of enterovirus protein specifically in pancreatic tissue immunopositive for VP1 by IHC with the Dako antibody has not been confirmed by other methods, and recently it was reported that, in the Network for Pancreatic Organ Donors with Diabetes (nPOD) cohort, there was no correlation between immunopositivity for VP1 and the presence of enterovirus genome as demonstrated by PCR [12]. These findings suggest that any evidence for an association between enterovirus and type 1 diabetes based on IHC with the Dako VP1 antibody should be disregarded.

The 'unbiased proteomic analysis' claimed in the article by Dunne et al to verify the presence of viral proteins in type 1 diabetic pancreases sounds interesting but is based on unpublished data only, and it is not clear whether the presence of VP1 correlates with IHC positivity or type 1 diabetes. A number of novel antibodies with demonstrated high specificity for structural $[15,17]$ and non-structural $[18]$ enterovirus proteins have been developed but, to date, none of these have been used to confirm the presence of enterovirus protein in the pancreas of individuals with type 1 diabetes.

Fifth, Dunne et al refer to studies claiming that staining for protein kinase $\mathrm{R}$ (PKR) overlaps more or less completely with staining for enterovirus VP1 [19] and argue that this is consistent with an innate immune response initiated by a chronic enterovirus infection. However, we recently demonstrated that PKR is expressed in the majority of cells in the pancreas, regardless of enterovirus infection [20]. In order to study a potential antiviral response inducing translational arrest in infected beta cells, methods that specifically detect active phosphorylated PKR need to be used. To our knowledge, this has not been performed to date in human pancreatic samples.

Sixth, evidence of persistent enterovirus infection in thyroid disease is weak and based on immunopositivity for VP1 using the same antibody clone as demonstrated to cross-react with cellular proteins in pancreatic [14] and heart [15] tissue. This must be considered when estimating the commercial viability of developing an enterovirus vaccine.

In summary, the evidence for the presence of enterovirus in islets predominantly from individuals with type 1 diabetes compared with non-diabetic control individuals is at best weak. However, we know that enteroviruses can infect beta cells in vitro and in vivo [21] and it is possible that such infections play a role in the induction of type 1 diabetes but are resolved at the time of clinical diagnosis. A viral aetiology of type 1 diabetes is still plausible as several observations are in line with this hypothesis, and we agree that intervention trials in type 1 diabetes directed against enterovirus could finally prove a causal relationship. However, type 1 diabetes is not likely to be caused by a single enterovirus strain or serotype and vaccination should therefore be as broad as possible. Therapy with antiviral drugs initiated after diagnosis of type 1 diabetes is less likely to have any effect, as the evidence of enterovirus infection in islets post diagnosis is weak. Overinterpretation and uncritical review of current evidence risks obscuring a real link between enterovirus and type 1 diabetes and damaging our common goal of understanding the aetiology of type 1 diabetes in order to prevent the disease. That said, we are looking forward to seeing the results of broad vaccination trials, which will hopefully prevent at least a fraction of type 1 diabetes cases.

Funding This work was supported by grants from the Swedish Medical Research Council (K2015-54X-12219-19-4, 921-2014-7054), the Sten A. Olsson Foundation, the Ernfors Family Fund, Barndiabetesfonden, the Swedish Diabetes Association, the Novo Nordisk Foundation, the Diabetes Wellness foundation, the Åke Wiberg foundation, the Tore Nilsson foundation, Helmsley Charitable Trust and the JDRF.

Duality of interest The authors declare that there is no duality of interest associated with this manuscript.

Contribution statement OS conceptualised and drafted the article. All authors were responsible for revising the article critically for important intellectual content. All authors approved the version to be published.

Publisher's note Springer Nature remains neutral with regard to jurisdictional claims in published maps and institutional affiliations.

\section{References}

1. Dunne JL, Richardson SJ, Atkinson MA et al (2019) Rationale for enteroviral vaccination and antiviral therapies in human type 1 diabetes. Diabetologia. https://doi.org/10.1007/s00125-019-4811-7 
2. Dotta F, Censini S, van Halteren AG et al (2007) Coxsackie B4 virus infection of beta cells and natural killer cell insulitis in recentonset type 1 diabetic patients. Proc Natl Acad Sci U S A 104(12): 5115-5120. https://doi.org/10.1073/pnas.0700442104

3. Drescher KM, Tracy SM (2008) The CVB and etiology of type 1 diabetes. Curr Top Microbiol Immunol 323:259-274

4. Chapman NM, Kim KS, Drescher KM, Oka K, Tracy S (2008) 5' terminal deletions in the genome of a coxsackievirus B2 strain occurred naturally in human heart. Virology 375(2):480-491. https://doi.org/10.1016/j.virol.2008.02.030

5. Coppieters KT, von Herrath MG (2009) Histopathology of type 1 diabetes: old paradigms and new insights. Rev Diabet Stud 6(2): 85-96. https://doi.org/10.1900/RDS.2009.6.85

6. Krogvold L, Edwin B, Buanes T et al (2015) Detection of a lowgrade enteroviral infection in the islets of Langerhans of living patients newly diagnosed with type 1 diabetes. Diabetes 64(5): 1682-1687. https://doi.org/10.2337/db14-1370

7. Krogvold L, Skog O, Sundstrom G et al (2015) Function of isolated pancreatic islets from patients at onset of type 1 diabetes: insulin secretion can be restored after some days in a nondiabetogenic environment in vitro: results from the DiViD study. Diabetes 64(7):2506-2512. https://doi.org/10.2337/db14-1911

8. Skog O, Ingvast S, Korsgren O (2014) Evaluation of RT-PCR and immunohistochemistry as tools for detection of enterovirus in the human pancreas and islets of Langerhans. J Clin Virol 61(2):242247. https://doi.org/10.1016/j.jcv.2014.07.014

9. Tracy S, Drescher KM, Chapman NM (2011) Enteroviruses and type 1 diabetes. Diabetes Metab Res Rev 27(8):820-823. https:// doi.org/10.1002/dmrr.1255

10. Buesa-Gomez J, de la Torre JC, Dyrberg T et al (1994) Failure to detect genomic viral sequences in pancreatic tissues from two children with acute-onset diabetes mellitus. J Med Virol 42(2):193197. https://doi.org/10.1002/jmv.1890420217

11. Tanaka S, Nishida Y, Aida K et al (2009) Enterovirus infection, CXC chemokine ligand 10 (CXCL10), and CXCR3 circuit: a mechanism of accelerated beta-cell failure in fulminant type 1 diabetes. Diabetes 58(10):2285-2291. https://doi.org/10.2337/db090091

12. Oikarinen M, Laiho JE, Oikarinen S et al (2018) Detection of enterovirus protein and RNA in multiple tissues from nPOD organ donors with type 1 diabetes. bioRxiv https://doi.org/10.1101/ 459347

13. Krogvold L, Genoni A, Puggioni A et al (2017) Enteroviruses in the pancreas of live adult patients with newly diagnosed type 1 diabetes. Results from the DiViD study. Diabetologia 60:S167 (Abstract)

14. Hansson SF, Korsgren S, Ponten F, Korsgren O (2013) Enteroviruses and the pathogenesis of type 1 diabetes revisited: cross-reactivity of enterovirus capsid protein (VP1) antibodies with human mitochondrial proteins. J Pathol 229(5):719-728. https:// doi.org/10.1002/path.4166

15. Ettischer-Schmid N, Normann A, Sauter M et al (2016) A new monoclonal antibody (Cox mAB 31A2) detects VP1 protein of coxsackievirus B3 with high sensitivity and specificity. Virchows Arch 469(5):553-562. https://doi.org/10.1007/s00428-016-2008-8

16. Richardson SJ, Leete P, Dhayal S et al (2014) Evaluation of the fidelity of immunolabelling obtained with clone 5D8/1, a monoclonal antibody directed against the enteroviral capsid protein, VP1, in human pancreas. Diabetologia 57(2):392-401. https://doi.org/10. 1007/s00125-013-3094-7

17. Saarinen NVV, Laiho JE, Richardson SJ et al (2018) A novel rat CVB1-VP1 monoclonal antibody 3A6 detects a broad range of enteroviruses. Sci Rep 8(1):33. https://doi.org/10.1038/s41598017-18495-4

18. Laitinen OH, Svedin E, Kapell S et al (2018) New coxsackievirus $2 \mathrm{~A}$ (pro) and $3 \mathrm{C}$ (pro) protease antibodies for virus detection and discovery of pathogenic mechanisms. J Virol Methods 255:29-37. https://doi.org/10.1016/j.jviromet.2018.02.001

19. Richardson SJ, Leete P, Bone AJ, Foulis AK, Morgan NG (2013) Expression of the enteroviral capsid protein VP1 in the islet cells of patients with type 1 diabetes is associated with induction of protein kinase R and downregulation of Mcl-1. Diabetologia 56(1):185193. https://doi.org/10.1007/s00125-012-2745-4

20. Jonsson A, Yngve E, Karlsson M, Ingvast S, Skog O, Korsgren O (2018) Protein kinase R is constitutively expressed in the human pancreas. J Histochem Cytochem 67(2):99-105

21. Ylipaasto P, Klingel K, Lindberg AM et al (2004) Enterovirus infection in human pancreatic islet cells, islet tropism in vivo and receptor involvement in cultured islet beta cells. Diabetologia 47(2):225-239. https://doi.org/10.1007/s00125-003-1297-z 